\title{
Review Article \\ Cross Talk between Cellular Regulatory Networks Mediated by Shared Proteins
}

\author{
Christine Dolde, Jiongming Lu, and Beat Suter \\ Institute of Cell Biology, University of Bern, Baltzerstraße 4, 3012 Bern, Switzerland \\ Correspondence should be addressed to Beat Suter; beat.suter@izb.unibe.ch
}

Received 4 March 2014; Accepted 2 June 2014; Published 25 June 2014

Academic Editor: Qianzheng Zhu

Copyright (C) 2014 Christine Dolde et al. This is an open access article distributed under the Creative Commons Attribution License, which permits unrestricted use, distribution, and reproduction in any medium, provided the original work is properly cited.

\begin{abstract}
Moonlighting proteins mediate cross talk between different pathways and cellular control networks. Sometimes, they even coordinate subsequent steps in the same pathway. For this Outlook paper we asked the question, which cellular processes employ multifunctional proteins (MFPs) and what makes them so attractive to cells and organisms. After reviewing their widespread occurrence, we will focus on higher eukaryotic model systems and on few examples that are linked to ongoing work in our laboratory. We will discuss the activities of transcription factor IIH (TFIIH), and its subcomplexes containing Xpd and Cdk7, and we will cover an aminoacyl-tRNA synthetase (LysRS) and DEAD box RNA helicases. Furthermore, we will analyze how cells are able to properly regulate the different biological activities of multifunctional proteins and which advantages such proteins offer to cells and organisms. Finally we also note that the proteins we discuss are linked to tumor formation or recruited by viruses that coopt the multifunctional protein for yet another purpose.
\end{abstract}

\section{Introduction}

For decades one hypothesis ruled most scientist's mind: one gene gives rise to one protein, which performs one specific role in the cell. Nowadays, this hypothesis gets severely challenged as there is increasing evidence that many proteins perform multiple functions and many cells seem to exploit the opportunities offered by these multitask proteins.

Numerous cellular control processes act simultaneously in the same cell and many proteins function in more than one control process. This realization has spurred our interest in finding out how cells take advantage of such dual- or even multifunctional proteins (MFPs). There are examples of dual roles that appear to be simple evolutionary "duplication steps" (Figure 1). Such MFPs can then be found in different protein complexes, which account for their different biological functions. In other cases, however, MFPs regulate parallel or subsequent cellular processes in a coordinated fashion (Figure 2). This points to a higher level of cellular control associated with the reuse of this protein. In yet other cases two alternative pathways share a component that is present only in limited amounts in the cell and this low abundance allows it to only function in one process at the time (Figure 3). In this case cells may use such a protein as a switch between two alternative processes, regulating them in an inverse manner.

In this outlook paper we briefly document how widespread MFPs are by covering some examples from single cell model systems. We will then focus on studies that used multicellular organisms and on aspects related to our own research. Using these examples we will provide a more in depth analysis of the roles of MFPs and on how cells and multicellular organisms take advantage of the multiple activities of these proteins.

Evolutionary Duplication Steps. Research with microorganisms has a long tradition of pioneering cellular control processes. With regard to MFPs, a recent publication nicely illustrates how MFPs are identified and shown to be functionally important [1]. The ubiquitin pathway targets intracellular proteins for degradation by the proteasome, a multiprotein complex that consists of over 30 subunits. Interestingly, the lid of the proteasome is an eight-subunit complex that bears homologies to COP9 signalosomes (CSN), a metalloprotease that consists of several subunits and regulates the activity of 


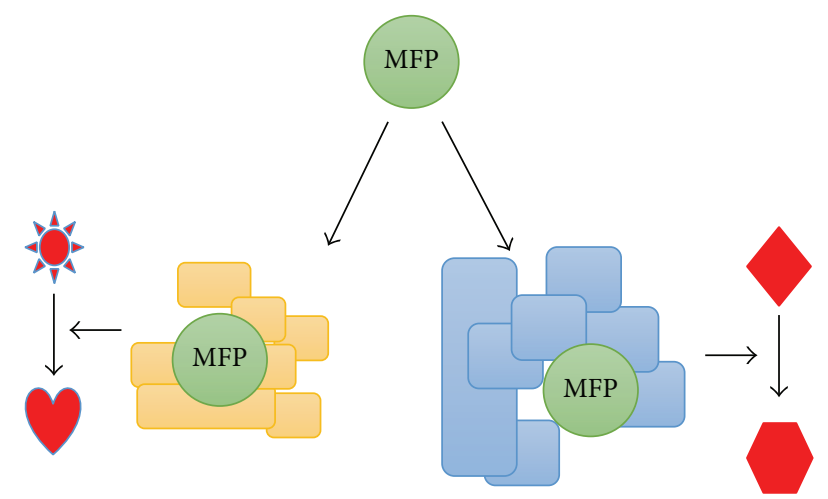

FIgURE 1: Evolutionary duplication steps. MFPs can be found in different complexes, promoting different activities. For example, RPN5 is a component of the CSN and the lid of the proteasome.

a family of E3 ubiquitin ligases. By comparing the proteasome lid to the CSN complex, the authors identified RPN5 (regulatory particle non-ATPase) as a common protein. Because RPN5 mutants show phenotypes indicative of proteasome and CSN defects, it seems that RPN5 plays critical functions as part of the CSN in addition to its essential roles in the proteasome. Rpn5 is required in the proteasome complex for proteolysis and in the CSN complex for cullin-derubylation (removal of Rub1/Nedd8). While this presently looks like a simple case of reusing a component that is associated with different activities (Figure 1), further work needs to test whether the organism takes advantage of this dual use.

Alternative Regulation of Different Cellular Processes. Bacterial survival depends mainly on sensing environmental changes. Helpful players are intracellular stress alarmones like guanosine tetraphosphate and guanosine pentaphosphate, (p)ppGpp, originally described as the "magic spot" [2, $3]$. They regulate the stringent response that consists of global gene regulatory changes leading to reduced metabolism and growth inhibition. Once conditions become more favorable again for bacterial growth, (p)ppGpp levels are downregulated and bacterial cells resume their biosynthetic activities and growth. In Gram-positive bacteria, production and hydrolysis of (p)ppGpp are regulated by the same bifunctional enzyme, Rel (Msm), which consists of a single polypeptide that is able to perform (p)ppGpp synthesis through its SYNTH domain and hydrolysis through a domain present at the $C$ terminus [4]. Interestingly, uncharged tRNA seems to regulate the activity of Rel (Msm). tRNA is able to bind to Rel and this induces a conformational change that favors (p)ppGpp synthesis. In this case, a mechanism of alternative or inverse regulation has evolved in which the presence of the two domains with inverse activity in a single polypeptide chain allows alternative activation of one of the two activities and inactivation of the second, thereby preventing futile cycles of (p)ppGpp synthesis and hydrolysis [5-7] (Figure 3(a)).

Coordinated Regulation of Successive Steps in the Same Biological Process. MFPs can also serve to coordinate successive cellular processes (Figure 2(a)). For instance, when cells

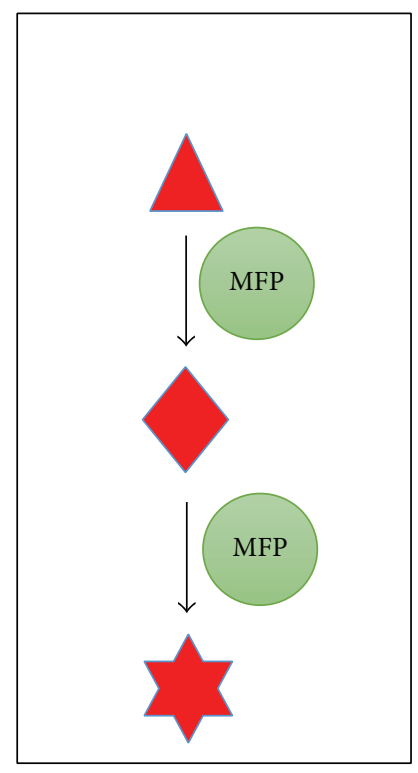

(a) Subsequent steps

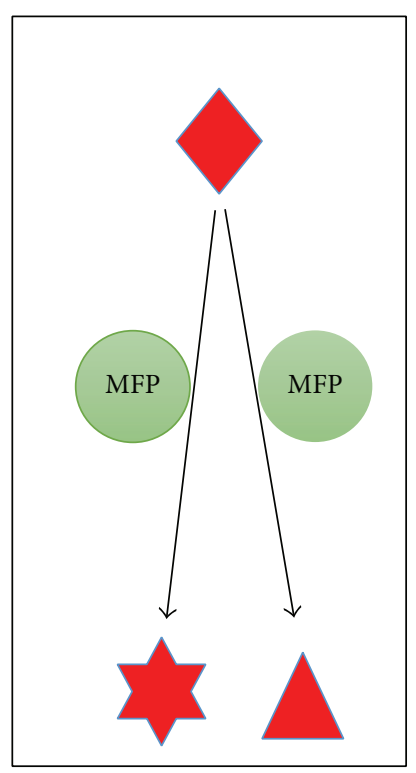

(b) Parallel steps
FIGURE 2: MFPs are involved in successive or parallel processes. If the amount of MFPs is not limited in the cell, they can be involved in multiple subsequent steps within one biological cascade (a). An example for this is Pex3p. In addition MFPs can promote two pathways simultaneously (b). As discussed in the text, the two parallel pathways may later converge onto a common purpose like promoting cell proliferation (this can be the case for Cdk7).

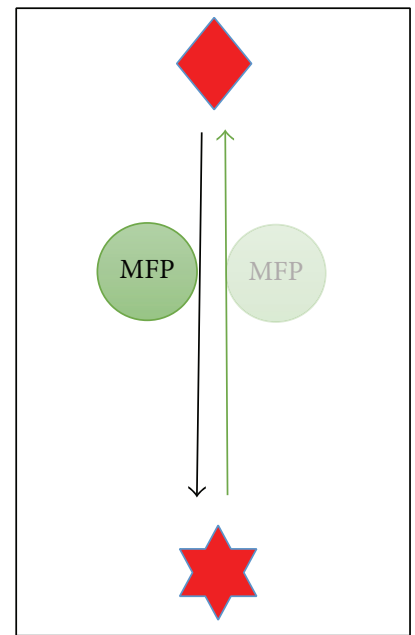

(a)

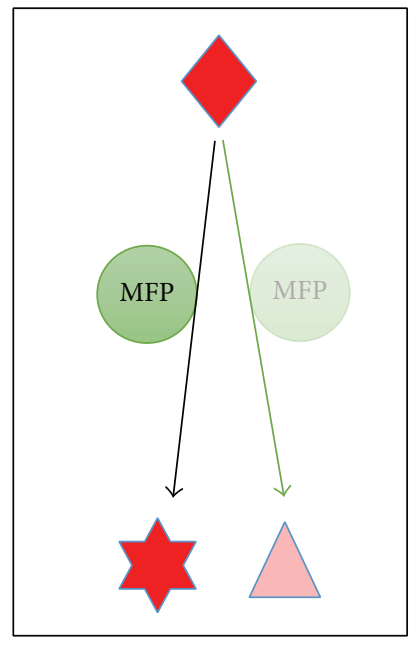

(b)
FIgURE 3: MFPs act as molecular switches by regulating alternative activities. If MFPs are limited in the cell, they only promote one pathway. There are cases where the same enzyme is able to promote or repress a specific path (a) and Rel (Msm) illustrates this example in the text. In other cases the MFP has the capacity to activate two alternative pathways and, if limited in its amount, it will activate one at the expense of another. In particular in the cases discussed here the proper regulation of the MFP activity is crucial. Discussed examples for this are the role of Xpd in steering the CAK activity and also LysRS. 
divide, they need to distribute their organelles to both daughter cells. The peroxisome is such a cellular organelle and in Saccharomyces cerevisiae PEX3 is one of the genes required first for peroxisome biogenesis and then for proper distribution of peroxisomes during cell division [8]. Promoting peroxisome biosynthesis, Pex3p first appears in the endoplasmic reticulum (ER). Subsequently it associates with a peripheral peroxisomal membrane protein Inplp to anchor the peroxisome at the cell periphery [9]. Lack of Pex3p or mutations that prevent interaction with Inplp result in a peroxisome retention defect and most peroxisomes are transported into the daughter cell [10].

\section{Activities of XPD and Cdk7 in and out of TFIIH}

An amazing variety of functions have been associated with the general transcription factor IIH (TFIIH) and, accordingly, the variety of differential regulation controlling these functions is impressive. We got interested in these processes by studying two TFIIH components, Cdk7 (cyclin-dependent kinase 7) and XPD (xeroderma pigmentosum D). Metazoan XPD is also called ERCC2 and functions in transcription, nucleotide excision repair (NER), cell cycle control, and even organization of the mitotic spindle and chromosome segregation [11-16]. XPD is a DNA helicase and its helicase activity is necessary for its NER function. On the other hand, XPD plays only a structural role in transcription, where it helps forming a stable TFIIH complex, and it acts as a molecular dispatcher for the Cdk-activating kinase complex CAK in its cell cycle function [16-19]. The XPD polypeptide can be isolated from several different complexes, including the TFIIH complex. TFIIH contains 9 additional polypeptides, p34, p44, p52, p62, XPB, TFB5 (also called TTD-A and p8), Cdk7, Cyclin H, and Mat1 [20-22]. This complex is also found split into two subcomplexes, the CAK subcomplex, consisting of the last three subunits (Cdk7, cyclin $\mathrm{H}$, and Mat1), and the core TFIIH with the other subunits. XPD itself can associate with both of these two subcomplexes, even though CAK is often found only as a trimer. Another XPD complex has been identified in mammalian cells. In this complex XPD is the only TFIIH subunit found in the complex and it associates with MMS19 and MIP18, which led to the complex name MMXD [14].

TFIIH and its subcomplexes are involved in the regulation of transcription, DNA repair, cell cycle progression, and chromosome segregation [11-15, 17]. This amazing number of different cellular complexes and processes, some of which are mutually exclusive, while others happen concurrently, captured our attention. The interplay between the different complexes and functions is only partially understood, and there does not seem to exist a single unifying mode of regulation. However, one important mode of regulating the different activities of XPD and the Cdk7 kinase is through forming complexes of different composition. The different TFIIH complexes and subcomplexes perform at least some of their different in vivo functions through structurally different complexes. The trimeric CAK (Cdk7/Cyclin H/Mat1) exhibits a strong substrate preference for the cell cycle targets, the
Cdks, and is less active against the $\mathrm{C}$-terminal domain (CTD) of RNA Polymerase II (PolII) and CTD peptides, whereas TFIIH-associated CAK preferentially phosphorylates the CTD [23-28].

2.1. Transcription and Cell Cycle Functions. The dual-use subunit CAK with the Cdk7 kinase allows the cell to prepare in a coordinated way for growth and proliferation activity. It does this by regulating the availability and activity of the CAK complex. Increasing CAK, for instance, through subunit synthesis, stabilization, or modification, would promote both pathways. It would stimulate transcription by providing ample TFIIH complexes and it would activate cell cycle Cdks by providing an excess of free CAK (Figure 2(b)). This mechanism seems to be at work in tumor cells because it was found that many tumors express elevated levels of Cdk7 compared to the corresponding normal cells [29]. In contrast to the simultaneous regulation and on a different time scale, cells can take advantage of the same duality of complexes and functions in a different way. As cells enter mitosis, they shut down transcription and simultaneously upregulate Cdk1 activity through different mechanisms $[19,30]$.

In this situation Drosophila XPD plays a decisive role during the embryonic division cycles. It regulates whether the trimeric CAK complex is associated with TFIIH, which promotes transcription activation by phosphorylating the CTD of PolII, or whether CAK is free and activates the cell cycle Cdks by phosphorylating their T-loop $[13,30]$. If in this situation XPD is the limiting factor in the cell, its removal from TFIIH simultaneously shuts down the transcription activity of TFIIH and releases free CAK to perform its Cdk1 T-loop phosphorylation function that activates the M-phase kinase. This dual-use of CAK corresponds to the alternative activity mode as depicted in Figure 3(b). As long as sufficient amounts of XPD are present, CAK is used in the protein complex TFIIH, leading to transcription promotion. Reducing the availability of XPD sets free the CAK complex to promote activation of cell cycle Cdks.

2.2. Transcription and DNA Repair. During PolII transcription, TFIIH associates with other TFIIs and with PolII, and it phosphorylates the CTD of PolII and TFIIE (reviewed in [31-33]). For its DNA repair function during NER TFIIH is recruited to the damage site by associating with repairspecific factors (CSA, CSB, or XPC/hHR23, reviewed by [34]). At this point, significant activity changes happen. TTDA is the tenth TFIIH subunit and it specifically functions in DNA repair. The interaction of TTDA with the TFIIH core components $\mathrm{p} 52$ and XPB stimulates the ATPase activity of XPB, anchoring TFIIH to the damaged DNA [20,35-38] reviewed in [16]. Once bound, the interaction between the other TFIIH components $\mathrm{p} 34, \mathrm{p} 44$, and XPD stimulates the XPD helicase activity $[39,40]$. Furthermore, the association with yet another NER component, XPA, causes CAK to disassociate from the core TFIIH [41] and the helicase activity of the TFIIH-bound XPD now locally unwinds the DNA and maybe also remodels PolII, giving the NER machinery access to the lesion $[18,42]$. Differential complex formation 
therefore decides whether TFIIH is active as transcription factor or in NER (Figure 3(b)).

2.3. Other Complexes and Functions. As the picture of these interwoven control mechanisms starts to take shape, novel pathways are still discovered. The role of the recently discovered MMXD complex in the control of XPD activity, chromatin segregation, and spindle organization is not clear yet [14]. While it was proposed that this XPD complex plays an active role in mitosis, the function of MMXD may also be to sequester XPD at the time when high CAK activity is required and TFIIH-dependent transcription becomes silenced. On the other hand, the finding that MMS19 is part of the cytosolic iron-sulfur (FeS, Fe/S) cluster assembly machinery (CIA) [43, 44] may also point to a more trivial involvement of MMS19 in supplying functional and stable XPD. The accumulation of this complex in mitosis may then simply reflect stalled assembly of functional XPD. Clearly, more work is needed to understand this part of the XPD network and its implication for controlling the various activities of XPD, Cdk7, and TFIIH.

\section{Lysyl-tRNA Synthetase: Multiple Functions in and Beyond Aminoacylation}

Lysyl-tRNA synthetase (LysRS) is a highly conserved enzyme involved in protein translation. It catalyzes the ligation of the amino acid lysine to its cognate tRNA, a process called aminoacylation [45]. The structure of LysRS has been solved and this provided many new insights into its function $[46,47]$. In its C-terminal aminoacylation domain, human LysRS contains the three consensus sequences (motif 1, 2, and 3) that are common to all class II aminoacyl-tRNA synthetases (aaRSs). In the N-terminal part, it is composed of the anticodon binding domain and an extra eukaryotic extension. The functional enzyme for aminoacylation is a homodimer, in which two molecules form in a symmetric way through the interface that involves the consensus motif 1 [47]. This canonical aminoacylation function of LysRS is essential for the development, survival, and reproduction of each cell, tissue, and organism [48, 49].

In higher eukaryotes LysRS forms several complexes, which link it to diverse biological processes [50,51]. Together with other aaRSs, LysRS can form a large complex, known as multisynthetase complex (MSC), which is composed of at least eight aaRSs and the three auxiliary factors AIMP1 (also known as p43), AIMP2 (also known as p38), and AIMP3 (also known as p18) [52-54]. In this complex LysRS dimers interact with the N-terminus of AIMP2 to form the LysRS/AIMP2 subcomplex $[55,56]$. The binding of LysRS to AIMP2 does not induce a conformational change and, because of this, the aminoacylation activity of LysRS remains similar when bound to the MSC $[47,57]$.

The exact function of the MSC is not clear, but it is thought to serve as a reservoir for cellular tRNA synthetases and to regulate their functions beyond aminoacylation [58, 59]. Due to its involvement in different signaling pathways, the MSC was described as "signalosome" [60]. Interestingly, the majority of LysRS in quiescent cells is associated with the MSC where it keeps its dimeric structure, and only a small fraction is present in the free form [61]. How this balance is controlled is still unclear. However, it seems that both forms are synchronously involved in protein translation. The MSC was shown to be essential for normal protein synthesis and for growth of mammalian cells, and it was also reported that the MSC per se is required for normal development in the mouse [62-64]. It therefore appears that the two different LysRS complexes may take on different functions in translation.

3.1. LysRS in Regulation of Transcription. LysRS is known to be the major contributor to the synthesis of $A_{4} A$ in mammals $[65,66] . \mathrm{Ap}_{4} \mathrm{~A}$, a diadenosine polyphosphate, is composed of two adenosines linked in a $5^{\prime}-5^{\prime}$ manner by a chain of four phosphates. This molecule is highly charged and can bind to proteins. In mast cells, the microphthalmia transcription factor (MITF) plays important roles in allergic reactions. Its transcription activity is repressed by its interaction with the repressor protein Hint- 1 in quiescent cells. Upon antigen-lgE induced activation of mast cells, the binding of $\mathrm{Ap}_{4}$ A to Hint-1 releases Hint-1 from MITF and therefore activates transcription from its target genes [67]. LysRS is crucial for this signaling and knocking down of LysRS abrogates the immune induction through $\mathrm{Ap}_{4} \mathrm{~A}$, resulting in low levels of MITF-target genes. It was demonstrated that LysRS forms a complex with MITF and Hint-1, leading to the local accumulation of $\mathrm{Ap}_{4} \mathrm{~A}$ [68]. Besides MITF, another ubiquitously expressed transcription factor, USF2, is also regulated by LysRS in this way [69].

LysRS is a cytoplasmic protein, and the transcription regulation occurs in the nucleus. The obvious question is therefore how LysRS translocates into the nucleus and from which pool this LysRS originates from. Recent studies showed that upon immunological challenge, LysRS is phosphorylated on Ser207, released from the MSC, and it translocates to the nucleus. The phosphorylation is carried out in a MAPKdependent manner, since a preincubation of cells with MAPK inhibitors prevented the phosphorylation, dissociation, and translocation of LysRS [61]. Also, the observation that the phosphomimetic mutant LysRS ${ }^{\text {S207D }}$ localizes constitutively to the nucleus, even in quiescent cells, indicates that the phosphorylation itself may be able to induce nuclear translocation [70].

A study published recently clarified in detail how LysRS switches functions from translation to transcription [70]. Phosphorylation of Ser207 triggers a conformational change of LysRS that opens its N-terminal tRNA anticodon-binding domain. This open conformation of LysRS disrupts its interaction with AIMP2, inducing its release from the MSC. In the nucleus, the Ser207 phosphorylation of LysRS is also crucial for $\mathrm{Ap}_{4} \mathrm{~A}$ synthesis. A first step leads to the generation of Lysyl-AMP, analogous to its activity in aminoacylation. In the second step, Lysyl-AMP interacts with a second ATP to form the $\mathrm{Ap}_{4} \mathrm{~A}$, and a Lys is released. The Ser207 phosphorylated LysRS with its open $\mathrm{N}$-terminal domain, specifically turns off the second step of aminoacylation and promotes $\mathrm{Ap}_{4} \mathrm{~A}$ synthesis, thus switching its function from translation to 
transcription. The switch to the transcriptional function has the potential to simultaneously interfere with translation if the amount of LysRS is limited (Figure 3(b)). Whether this is the case and whether the switch indeed affects translation in vivo still needs to be tested.

3.2. LysRS in HIV Infection. During HIV-1 infection, the human cytoplasmic isoacceptors, tRNA ${ }^{\text {Lys1 }}, \mathrm{tRNA}^{\mathrm{Lys} 2}$, and $\mathrm{tRNA}^{\text {Lys3 }}$ are selectively packaged into the virus and tRNA ${ }^{\text {Lys3 }}$ serves as the primer for reverse transcription of the viral RNA. The incorporation of tRNA ${ }^{\text {Lys }}$ into HIV-1 seems to be mediated by its binding to LysRS, which can further interact with the viral precursor protein Gag and also be packaged into the virus [71-73]. The interaction between LysRS and Gag was mapped to the consensus motif 1 of LysRS and the C-terminal domain (CTD) of the capsid, a mature protein processed from Gag $[74,75]$. Additional presence of the viral precursor protein Gag-Pol, which interacts with $\mathrm{tRNA}^{\mathrm{Lys}}$ as well, is also needed for tRNA ${ }^{\text {Lys }}$ packaging and might be able to stabilize the Gag/LysRS/tRNA ${ }^{\text {Lys }}$ complex $[76,77]$. In this way, LysRS plays an important role in the HIV-1 infection cycle.

Based on several observations it is clear that the role of LysRS in HIV-1 infection is not dependent on its aminoacylation activity. First, C-terminally truncated LysRS, which is able to bind to tRNA ${ }^{\text {Lys }}$, but cannot aminoacylate it, still packages tRNA ${ }^{\text {Lys }}$ into virions [78]. Second, as mentioned above, the interaction between Gag and LysRS was mapped to the consensus motif 1 , which overlaps with the core dimerization domain, indicating that LysRS interacts with Gag as a monomer, which is inactive in aminoacylation. And finally, a recent study demonstrated that monomeric LysRS binds to Gag and tRNA ${ }^{\text {Lys }}$ [75]. Although its aminoacylation activity is not necessary, the ability of LysRS to bind to $\mathrm{tRNA}^{\text {Lys }}$ is required for packaging. The source of LysRS that gets recruited for virion packaging remains to be determined. It is not known yet whether it originates from the free LysRS pool or is released from the MSC.

During HIV-1 amplification, the cellular dimeric LysRS converts to a monomer that switches off or loses the aminoacylation activity, forms the Gag/LysRS/tRNA ${ }^{\text {Lys }}$ complex and is packaged as such into virions. Because these processes are sensitive to alterations of LysRS level [79], it appears that LysRS is limiting. As a consequence, the recruitment of LysRS into the virus acts as a functional switch from translation to virion assembly (Figure 3(b)).

In summary, LysRS is an ancient enzyme that performs multiple functions and at least two different mechanisms act on LysRS to regulate it by turning a functional switch. Competition for protein interactions through a single domain and phosphorylation induced conformational changes control its involvement in different pathways. Adding to the palette of LysRS functions, it was recently shown that LysRS can also be secreted as a cytokine-like molecule from certain cancer cell lines and that it is also involved in cancer cell migration $[80,81]$. Due to its diverse functions, the malfunctioning of LysRS facilitates many types of diseases, including HIV infection, cancers, immunological diseases, and also neurodegenerative diseases [51]. Therefore, LysRS serves as an interesting example to demonstrate how one protein forms different complexes and plays roles in different multicellular processes in physiological and pathological conditions.

\section{Multiple Functions of DEAD Box RNA Helicases}

DEAD box RNA helicases are multifunctional proteins in the context of RNA linked processes [82]. These ancient and highly conserved RNA helicases, characterized by their shared motif Asp-Glu-Ala-Asp (DEAD), can be found in all three kingdoms of life and have been studied in several eukaryotic and prokaryotic systems [83]. The first discovered DEAD box RNA helicase was the eukaryotic translation initiation factor $4 \mathrm{~A}$ (eIF4A). It was initially described together with other translation initiation factors to recruit the small ribosomal subunit to the $5^{\prime}$ cap structure of RNA. Later, it was shown that eIF4A contains an RNA induced ATPase activity which results in local unwinding of RNA strands (reviewed in [84]).

In general, DEAD box RNA helicases use ATP to bind or remodel RNA or RNA-protein complexes [85]. It is noteworthy, that many DEAD box helicases have no enzymatic activity despite their sequence similarity. Instead, they function as anchors for protein complexes, as RNP (ribonucleoprotein) remodeling enzymes, as catalysts for RNA folding, and as RNA transporters (reviewed in [86]). Just recently, DEAD box proteins were discovered to function in cell-to-cell communication independent of their previously described RNA-associated functions [87, 88]. This outlook focuses on DEAD box RNA helicases 3 and 5 (DDX3 and DDX5/p68, resp.) and their various biological functions within several protein complexes.

4.1. RNA-Linked Processes Involving DDX3 and DDX5/p68. Both RNA helicases are members of the DEAD box RNA helicase family with demonstrated RNA helicase activity [89, 90]. The possible mechanism by which DEAD box RNA helicases denature double strand RNA has been elucidated with yet another DEAD box protein, Vasa. In the presence of ATP, the substrate RNA, in this case a single strand RNA (ssRNA), is bent by an alpha helix typical for the Nterminal domain of DEAD-box proteins [91]. It has been suggested that this "kinked" RNA structure is only possible with ssRNA and not for dsRNA. The authors speculate that due to the structural information dsRNA can be locally denatured, which leads to the unwinding of short dsRNA or secondary structures in ssRNA.

DDX3 and DDX5/p68 are both required for several steps during gene expression. DDX3 is involved in transcription, RNA maturation, RNA export, mRNA translation, and even RNA storage (reviewed in [82]). DDX5/p68 is involved in transcription, RNA maturation and RNA decay (reviewed in [92]). Their multifunctionality within one pathway is another example of how proteins are used for the successive 
coordination of cellular processes (see Figure 2(a)). Interestingly, the transcriptional function of DDX3 takes place at the promoter, whereas DDX5/p68 interacts with transcription factors and affects transcription indirectly. Chromatinimmunoprecipitation experiments revealed that DDX3 binds to the promoter region of E-cadherin and IFN $\beta$. Surprisingly, DDX3 upregulates the expression of IFN $\beta$, but downregulates the E-cadherin expression [93-95]. How DDX3 targets specific promoter regions, whether it gets recruited to these sites by transcription factors, and why it can have different effects on different promoters remain to be determined. DDX5/p68 can also play a positive or a negative role in transcription independent of its helicase activity (reviewed in [92]). It acts as a cofactor for transcription factors including the nuclear hormone receptor estrogen receptor alpha (ER $\alpha)$ [96] and as a corepressor by interacting with histone deacetylase 1 (HDAC1), a well-established transcriptional repressor protein [97].

The involvement of DDX at the next level of gene expression was revealed by studies performed in yeast. The DDX3 homolog Dedlp interacts with the spliceosome and is involved in RNA maturation [98]. A genome wide microarray analysis corroborated its function in mRNA splicing [99]. DDX5/p68 is involved in pre-mRNA splicing, alternative splicing, rRNA processing, and miRNA processing (reviewed in [92]). The next step of gene expression involving DDX3 and DDX5/p68 is the nuclear export of RNA. One intriguing observation was that several viruses coopt this particular function of DDX3 and DDX5/p68 to export their viral RNA from the nucleus to the cytoplasm [100-103].

Several groups implicated DDX3 in mRNA translation once the mRNAs arrive in the cytoplasm [104, 105]. Yeast Dedlp is required together with other translation initiation factors (e.g., eIF4e, eIF4a, eIF2 $\alpha$, PABP, and eIF3) for unwinding $5^{\prime}$ untranslated regions (UTRs) to facilitate protein synthesis (reviewed in [106]). While the involvement of DDX3 in translation has been demonstrated, this function does not seem to affect mRNAs globally but seems rather restricted to the translation of specific mRNAs. At the end of the expression of an mRNA, DDX3, together with other RNA helicases like DDX5/p68, finally plays a role in RNA storage and clearance [107-110]. The involvement of DDX3 and DDX5/p68 during gene expression reflects the multifunctionality of one single protein, which displays its functions at different epistatic levels within the same pathway, gene expression. In most cases DDX helicases seem to promote gene expression at different levels, teaming up with different protein complexes (Figure 2(a)).

4.2. DDX3 and DDX5 in Cell-to-Cell Communication. Despite decades of studies of their RNA-associated functions, only recently DDX3 and DDX5/p68 were associated with the prominent $\mathrm{Wnt} / \beta$-catenin signaling pathway $[87,88]$. This signaling pathway controls complex cell behaviors throughout embryonic development, including cell proliferation, stem cell maintenance, and cell fate decisions. In 2006, Yang et al. [87] provided the first evidence that a DEAD box RNA helicase plays a role in Wnt signaling.
DDX5/p68 acts within this signaling cascade as an activator independently of the ligand Wnt itself [87]. DDX5/p68 becomes stimulated via phosphorylation by platelet-derived growth factors (PDGF). It displaces the inhibitor protein axin from $\beta$-catenin, blocks the phosphorylation of $\beta$ catenin, which would otherwise lead to the proteasomal degradation of the latter, and enables $\beta$-catenin to shuttle into the nucleus in order to promote transcription of Wnt target genes. Therefore, DDX5/p68 is not required for Wnt signaling, but it modulates the pathway and links it to PDGF signaling. In contrast, DDX3 is required for Wnt signaling [88]. It binds to the casein kinase 1 isoform epsilon $(\mathrm{CK} 1 \varepsilon)$ and stimulates the velocity of the kinase. This results in the Wnt-dependent phosphorylation of the signal transducing protein Dishevelled and leads to the $\beta$-catenin dependent transcription of Wnt target genes. Interestingly, the interaction of endogenous DDX3 and $\mathrm{CK} 1 \varepsilon$ is insensitive to RNase treatment, corroborating that this novel biological function cannot be linked to its RNA binding ability. Concluding from this study, only the protein structure of DDX3 is required for Wnt $/ \beta$-catenin signaling, while the enzymatic activity of the helicase is dispensable [88].

\subsection{Modifications of DDX Proteins Seem to Discriminate} between Their Different Biological Functions. The multifunctionality of DEAD box RNA helicases led to the question of how these different functions are called upon and executed. For DDX3 it is not known yet, whether it still performs its role in RNA-associated processes when it is active in Wnt signaling. We also do not know yet what might trigger these different biological functions. Notably, the enzymatic activity of DDX3 is dispensable for its function in cell-to-cell communication. This is an interesting parallel to the DNA helicase XPD, which requires its enzymatic activity for NER, but only its structural function for transcription.

Regarding DDX5/p68, Yang and coworkers [87] tested whether the ATPase and helicase activity was necessary for DDX5/p68's "Axin-displacement activity" by introducing point mutations in the C-terminal helicase region. Because these mutations affected both activities, it appears that ATPase and helicase activities may be required for axindisplacement. However, it cannot be ruled out that the mutations affected the structure of the whole C-terminal helicase domain. In the case of DDX3, the ATPase activity is clearly not required for its function in Wnt signaling because deletion of the $\mathrm{N}$-terminal helicase region abolishes the ATPase activity but leaves Wnt signaling intact.

How are these two DEAD box RNA helicases regulated to function on one hand during gene expression $[105,111$, 112 ] and on the other hand in cell-to-cell communication $[87,88]$. One hint comes from the observation that DDX5/p68 contains many posttranslational modifications. It is phosphorylated, acetylated, and sumoylated $[92,113,114]$. These modifications affect its interaction with other proteins and thereby steer its activity towards different biological processes. DDX5/p68 becomes phosphorylated in response to PDGF stimulation [87] and the responsible kinase may 


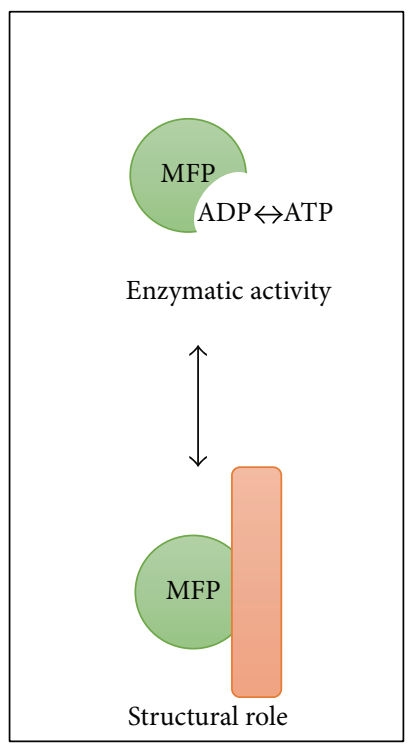

(a) Enzymatic activity versus structural role

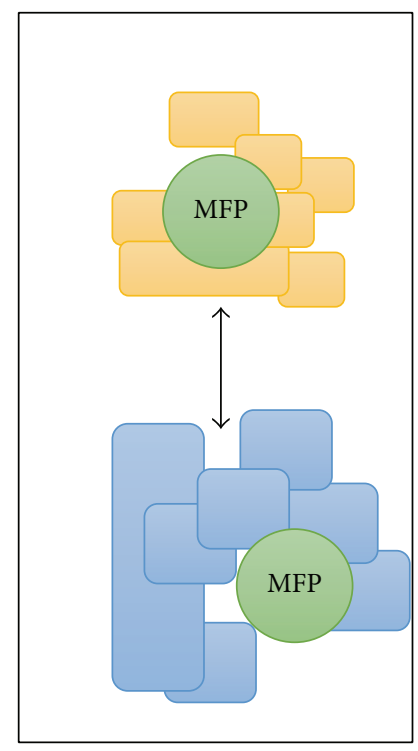

(b) Different protein complexes

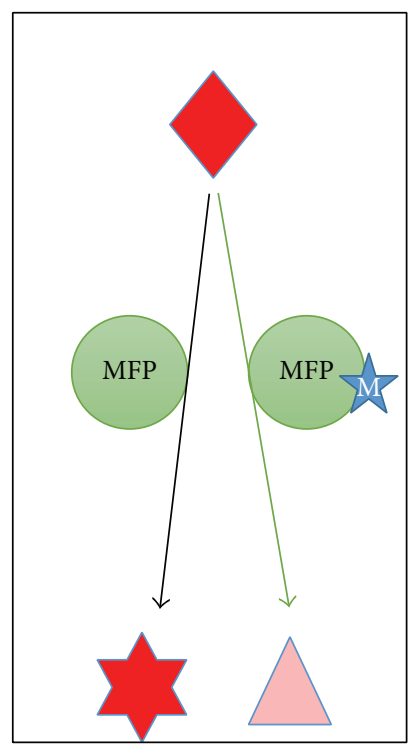

(c) Conformational changes

FIgURE 4: Possible mechanisms of MFP regulation. MFPs perform their function in the cell either by applying their enzymatic activity or simply through their structural function, for instance, as scaffold proteins (a). Furthermore, MFPs often associate with alternative proteins, which trap them in individual protein complexes to perform specific roles (b). Finally, MFPs can be regulated by modifications or molecular interactions that affect their conformation. Conformational changes may block one of their activity (e.g., the enzymatic activity) or block the formation of one of the complexes. In this way the conformational change may promote one of the pathways over the other (c).

be p38 MAP kinase. The MAP kinase phosphorylation target site on DDX5/p68 is crucial for its function in facilitating nuclear translocation of $\beta$-catenin [114]. Further studies showed that phosphorylation of tyrosines in the Cterminal domain of DDX5/p68 abolish its RNA unwinding activity [114]. Therefore, there are clear indications that the different modifications of DDX5/p68 regulate its biological activity. The combined effects of phosphorylation of the Cterminal helicase domain by p38 MAP kinase and a tyrosine kinase resemble molecular switches directing the different DDX5/p68 functions.

Interestingly, DDX3 is also phosphorylated by $\mathrm{CK} 1 \varepsilon$ in vitro. However, further work needs to clarify whether this phosphorylation is relevant for DDX3 function in vivo and whether this affects its RNA helicase activity. An interesting observation was made by discovering that both DEAD box RNA helicases, DDX3 and DDX5/p68, are able to interact with each other [115]. They seem to interact throughout the cell cycle, however, with changing affinities. The dynamics of their interactions was linked to the phosphoisoform pattern, which seems to change for both DEAD box proteins over the cell cycle [115]. It appears that these phosphorylation events could be relevant to control points because phosphatase treatment of both RNA helicases led to an enhancement of their interaction. Remarkably, during G2/M phase, when Wnt/ $\beta$-catenin signaling is highly active [116], serine phosphorylation levels of DDX3 are low [115], suggesting that the CK1 1 binding to DDX3, which happens primarily during active Wnt signaling [88], prevents S/T phosphorylation of DDX3. However, further experiments are needed to shed more light on how DEAD box RNA helicases switch between RNA-associated mechanisms and protein-protein interactions wherein ATP hydrolysis is mostly not required.

When considering the different functions of DEAD box RNA helicases, an evolutionary consideration may shed some light on how this type of molecule was able to assume such different molecular activities and functions. DEAD box RNA helicases are present in all metazoans as well as in singlecell organisms like yeast and even in prokaryotes like $E$. coli and Staphylococcus. However, cell-to-cell communication like Wnt signaling does not occur in single-celled organisms [117-119]. It is therefore intriguing to speculate that during the evolution of cell-to-cell communication in multicellular organisms DEAD box RNA helicases were coopted and used in an RNA independent manner.

\section{Conclusion}

XPD, LysRS, as well as DEAD box proteins are multifunctional proteins, involved in a myriad of biological activities. Analyzing them in more detail revealed several commonalities. First, these enzymes do not require their enzymatic activity for every function. Second, they interact with different protein complexes, which direct their multifunctional potential into specific biological processes. Third, modifications like phosphorylation often regulate their interaction affinities and thereby their activities. This (re)directs their activity into one particular pathway (Figure 4).

We noted that there are at least three modes in which MFPs work. For some, there is no obvious connection 
between their activity (Figure 1) other than the common function or structure of the MFP. This could represent an early step in the evolution of a MFP or an early phase in its exploration by scientists. We also found cases where MFPs promote subsequent steps in a workflow (Figure 2(a)), like a conveyor belt or a peristaltic pump that keeps the flow at different steps in the process. These functions can either be performed by the same activity or by utilizing two different activities of the MFP, for example, once the structural and once the enzymatic function. A prerequisite for being able to promote several different steps is that this promoting factor, the MFP, is not limited in the cell (Figure 2). Finally, when MFPs and factors that control their activity become limited, a MFP may only be available for one of its functions. In such cases the MFP acts as a molecular switch (Figure 3). From these models it is evident that even simple quantitative aspects such as abundance of the MFP can decide the final output of an MFP. For instance, as shown in Figure 2(b), as long as there is ample MFP available, it can support two processes in the cell. However, when MFP becomes limited, as depicted in Figure 3, then it will preferentially promote the pathway for which it has the higher affinity.

Our analysis of MFPs presented here also revealed that complex dynamics repeatedly plays crucial roles in regulating the multiple functions properly (Figure 4 ). These alternative interactions are often regulated by posttranslational modifications and can be accompanied by differential subcellular localization. For the proper study of such events we need to find out which complexes form in which compartment of a cell and monitor the activity of the MFP in different environments. Here lies a big challenge for the future to develop more quantitative tools to monitor subcellular activities and complexes. While such tools are being developed for some applications, many more need to follow and will have to be made suitable for living cells or even organisms.

\section{Conflict of Interests}

The authors declare that there is no conflict of interests regarding the publication of this paper.

\section{Authors' Contribution}

Christine Dolde and Jiongming Lu contributed equally to this paper.

\section{Acknowledgments}

This work was supported by the Swiss Cancer League, the Swiss National Science Foundation, the Canton of Bern, and an $\mathrm{EMBO}$ postdoctoral fellowship to $\mathrm{CD}$.

\section{References}

[1] Z. Yu, O. Kleifeld, A. Lande-Atir et al., "Dual function of Rpn5 in two PCI complexes, the $26 \mathrm{~S}$ proteasome and COP9 signalosome," Molecular Biology of the Cell, vol. 22, no. 7, pp. 911-920, 2011.
[2] L. U. Magnusson, A. Farewell, and T. Nyström, "ppGpp: a global regulator in Escherichia coli," Trends in Microbiology, vol. 13, no. 5, pp. 236-242, 2005.

[3] A. Srivatsan and J. D. Wang, "Control of bacterial transcription, translation and replication by (p)ppGpp," Current Opinion in Microbiology, vol. 11, no. 2, pp. 100-105, 2008.

[4] G. C. Atkinson, T. Tenson, and V. Hauryliuk, "The RelA/SpoT Homolog (RSH) superfamily: distribution and functional evolution of ppgpp synthetases and hydrolases across the tree of life," PLoS ONE, vol. 6, no. 8, Article ID e23479, 2011.

[5] T. Hogg, U. Mechold, H. Malke, M. Cashel, and R. Hilgenfeld, "Conformational antagonism between opposing active sites in a bifunctional RelA/SpoT homolog modulates (p)ppGpp metabolism during the stringent response," Cell, vol. 117, no. 1, pp. 57-68, 2004.

[6] V. Jain, R. Saleem-Batcha, A. China, and D. Chatterji, "Molecular dissection of the mycobacterial stringent response protein Rel," Protein Science, vol. 15, no. 6, pp. 1449-1464, 2006.

[7] V. Jain, R. Saleem-Batcha, and D. Chatterji, "Synthesis and hydrolysis of pppGpp in mycobacteria: a ligand mediated conformational switch in Rel," Biophysical Chemistry, vol. 127, no. 1-2, pp. 41-50, 2007.

[8] D. Hoepfner, M. van den Berg, P. Philippsen, H. F. Tabak, and E. H. Hettema, "A role for Vpslp, actin, and the Myo2p motor in peroxisome abundance and inheritance in Saccharomyces cerevisiae," Journal of Cell Biology, vol. 155, no. 6, pp. 979-990, 2001.

[9] M. Fagarasanu, A. Fagarasanu, Y. Y. C. Tam, J. D. Aitchison, and R. A. Rachubinski, "Inplp is a peroxisomal membrane protein required for peroxisome inheritance in Saccharomyces cerevisiae," Journal of Cell Biology, vol. 169, no. 5, pp. 765-775, 2005.

[10] J. M. Munck, A. M. Motley, J. M. Nuttall, and E. H. Hettema, "A dual function for Pex3p in peroxisome formation and inheritance," Journal of Cell Biology, vol. 187, no. 4, pp. 463-471, 2009.

[11] P. Frit, E. Bergmann, and J.-M. Egly, “Transcription factor IIH: a key player in the cellular response to DNA damage," Biochimie, vol. 81, no. 1-2, pp. 27-38, 1999.

[12] J.-M. Egly, “The 14th Datta Lecture. TFIIH: from transcription to clinic," FEBS Letters, vol. 498, no. 2-3, pp. 124-128, 2001.

[13] J. Chen, S. Larochelle, X. Li, and B. Suter, "Xpd/Ercc2 regulates CAK activity and mitotic progression," Nature, vol. 424, no. 6945, pp. 228-232, 2003.

[14] S. Ito, L. J. Tan, D. Andoh et al., "MMXD, a TFIIH-independent XPD-MMS19 protein complex involved in chromosome segregation," Molecular Cell, vol. 39, no. 4, pp. 632-640, 2010.

[15] X. Li, O. Urwyler, and B. Suter, "Drosophila Xpd regulates Cdk7 localization, mitotic kinase activity, spindle dynamics, and chromosome segregation," PLoS Genetics, vol. 6, no. 3, Article ID e1000876, 2010.

[16] J.-M. Egly and F. Coin, "A history of TFIIH: two decades of molecular biology on a pivotal transcription/repair factor," DNA Repair, vol. 10, no. 7, pp. 714-721, 2011.

[17] A. R. Lehmann, “The xeroderma pigmentosum group D (XPD) gene: one gene, two functions, three diseases," Genes and Development, vol. 15, no. 1, pp. 15-23, 2001.

[18] A. H. Sarker, S. E. Tsutakawa, S. Kostek et al., "Recognition of RNA polymerase II and transcription bubbles by XPG, CSB, and TFIIH: insights for transcription-coupled repair and Cockayne syndrome," Molecular Cell, vol. 20, no. 2, pp. 187-198, 2005. 
[19] E. Cameroni, K. Stettler, and B. Suter, "On the traces of XPD: cell cycle matters-untangling the genotype-phenotype relationship of XPD mutations," Cell Division, vol. 5, article 24, 2010.

[20] G. Giglia-Mari, F. Coin, J. A. Ranish et al., "A new, tenth subunit TFIIH is responsible for the DNA repair syndrome trichothiodystrophy group A," Nature Genetics, vol. 36, no. 7, pp. 714-719, 2004.

[21] P. Schultz, S. Fribourg, A. Poterszman, V. Mallouh, D. Moras, and J. M. Egly, "Molecular structure of human TFIIH," Cell, vol. 102, no. 5, pp. 599-607, 2000.

[22] J. A. Ranish, S. Hahn, Y. Lu et al., "Identification of TFB5, a new component of general transcription and DNA repair factor IIH," Nature Genetics, vol. 36, no. 7, pp. 707-713, 2004.

[23] M. Rossignol, I. Kolb-Cheynel, and J.-M. Egly, "Substrate specificity of the cdk-activating kinase (CAK) is altered upon association with TFIIH," EMBO Journal, vol. 16, no. 7, pp. 16281637, 1997

[24] K. Y. Yankulov and D. L. Bentley, "Regulation of CDK7 substrate specificity by MAT1 and TFIIH," EMBO Journal, vol. 16, no. 7, pp. 1638-1646, 1997.

[25] S. Larochelle, J. Chen, R. Knights et al., "T-loop phosphorylation stabilizes the CDK7-cyclin H-MAT1 complex in vivo and regulates its CTD kinase activity," EMBO Journal, vol. 20, no. 14, pp. 3749-3759, 2001.

[26] R. P. Fisher, "Secrets of a double agent: CDK7 in cell-cycle control and transcription," Journal of Cell Science, vol. 118, part 22, pp. 5171-5180, 2005.

[27] S. Larochelle, J. Batliner, M. J. Gamble et al., "Dichotomous but stringent substrate selection by the dual-function Cdk7 complex revealed by chemical genetics," Nature Structural and Molecular Biology, vol. 13, no. 1, pp. 55-62, 2006.

[28] R. P. Fisher, "The CDK network: linking cycles of cell sdivision and gene expression," Genes and Cancer, vol. 3, no. 11-12, pp. 731$738,2012$.

[29] J. Bartkova, M. Zemanova, and J. Bartek, "Expression of CDK7/CAK in normal and tumor cells of diverse histogenesis, cell-cycle position and differentiation," International Journal of Cancer, vol. 66, no. 6, pp. 732-737, 1996.

[30] J. Chen and B. Suter, "Xpd, a structural bridge and a functional link," Cell Cycle, vol. 2, no. 6, pp. 503-506, 2003.

[31] K. Glover-Cutter, S. Larochelle, B. Erickson et al., "TFIIHassociated Cdk7 kinase functions in phosphorylation of Cterminal domain Ser7 residues, promoter-proximal pausing, and termination by RNA polymerase II," Molecular and Cellular Biology, vol. 29, no. 20, pp. 5455-5464, 2009.

[32] B. N. Devaiah and D. S. Singer, "Cross-talk among RNA polymerase II kinases modulates C-terminal domain phosphorylation," The Journal of Biological Chemistry, vol. 287, no. 46, pp. 38755-38766, 2012.

[33] S. Larochelle, R. Amat, K. Glover-Cutter et al., "Cyclindependent kinase control of the initiation-to-elongation switch of RNA polymerase II," Nature Structural and Molecular Biology, vol. 19, no. 11, pp. 1108-1115, 2012.

[34] V. Oksenych and F. Coin, "The long unwinding road: XPB and XPD helicases in damaged DNA opening," Cell Cycle, vol. 9, no. 1, pp. 90-96, 2010.

[35] W. Vermeulen, E. Bergmann, J. Auriol et al., "Sublimiting concentration of TFIIH transcription/DNA repair factor causes TTD-A trichothiodystrophy disorder," Nature Genetics, vol. 26, no. 3, pp. 307-313, 2000.
[36] G. Giglia-Mari, C. Miquel, A. F. Theil et al., "Dynamic interaction of TTDA with TFIIH is stabilized by nucleotide excision repair in living cells," PLoS Biology, vol. 4, no. 6, article e156, 2006.

[37] V. Oksenych, B. B. de Jesus, A. Zhovmer, J.-M. Egly, and F. Coin, "Molecular insights into the recruitment of TFIIH to sites of DNA damage," EMBO Journal, vol. 28, no. 19, pp. 2971-2980, 2009.

[38] Y. Zhou, H. Kou, and Z. Wang, "Tfb5 interacts with Tfb2 and facilitates nucleotide excision repair in yeast," Nucleic Acids Research, vol. 35, no. 3, pp. 861-871, 2007.

[39] F. Coin, J.-C. Marinoni, C. Rodolfo, S. Fribourg, A. M. Pedrini, and J.-M. Egly, "Mutations in the XPD helicase gene result in $\mathrm{XP}$ and TTD phenotypes, preventing interaction between XPD and the p44 subunit of TFIIH," Nature Genetics, vol. 20, no. 2, pp. 184-188, 1998.

[40] S. Dubaele, L. P. de Santis, R. J. Bienstock et al., "Basal transcription defect discriminates between xeroderma pigmentosum and trichothiodystrophy in XPD patients," Molecular Cell, vol. 11, no. 6, pp. 1635-1646, 2003.

[41] F. Coin, V. Oksenych, V. Mocquet, S. Groh, C. Blattner, and J. M. Egly, "Nucleotide excision repair driven by the dissociation of CAK from TFIIH," Molecular Cell, vol. 31, no. 1, pp. 9-20, 2008.

[42] F. Coin, V. Oksenych, and J.-M. Egly, "Distinct roles for the $\mathrm{XPB} / \mathrm{p} 52$ and $\mathrm{XPD} / \mathrm{p} 44$ subcomplexes of TFIIH in damaged DNA opening during nucleotide excision repair," Molecular Cell, vol. 26, no. 2, pp. 245-256, 2007.

[43] K. Gari, A. M. León Ortiz, V. Borel, H. Flynn, J. M. Skehel, and S. J. Boulton, "MMS19 links cytoplasmic iron-sulfur cluster assembly to DNA metabolism," Science, vol. 337, no. 6091, pp. 243-245, 2012

[44] N. van Wietmarschen, A. Moradian, G. B. Morin, P. M. Lansdorp, and E.-J. Uringa, "The mammalian proteins MMS19, MIP18, and ANT2 are involved in cytoplasmic iron-sulfur cluster protein assembly," The Journal of Biological Chemistry, vol. 287, no. 52, pp. 43351-43358, 2012.

[45] P. R. Schimmel and D. Söll, "Aminoacyl-tRNA synthetases: general features and recognition of transfer RNAs," Annual Review of Biochemistry, vol. 48, no. 1, pp. 601-648, 1979.

[46] G. Desogus, F. Todone, P. Brick, and S. Onesti, "Active site of lysyl-tRNA synthetase: structural studies of the adenylation reaction," Biochemistry, vol. 39, no. 29, pp. 8418-8425, 2000.

[47] M. Guo, M. Ignatov, K. Musier-Forsyth, P. Schimmel, and X.L. Yang, "Crystal structure of tetrameric form of human lysyltRNA synthetase: implications for multisynthetase complex formation," Proceedings of the National Academy of Sciences of the United States of America, vol. 105, no. 7, pp. 2331-2336, 2008.

[48] K. P. Schäfer and D. Söll, "New aspects in tRNA biosynthesis," Biochimie, vol. 56, no. 6-7, pp. 795-804, 1974.

[49] M. Ibba and D. Söll, "Aminoacyl-tRNA synthesis," Annual Review of Biochemistry, vol. 69, no. 1, pp. 617-650, 2000.

[50] M. Guo, X.-L. Yang, and P. Schimmel, "New functions of aminoacyl-tRNA synthetases beyond translation," Nature Reviews Molecular Cell Biology, vol. 11, no. 9, pp. 668-674, 2010.

[51] A. Motzik, H. Nechushtan, S. Y. Foo, and E. Razin, "Noncanonical roles of lysyl-tRNA synthetase in health and disease," Trends in Molecular Medicine, vol. 19, no. 12, pp. 726-731, 2013.

[52] A. K. Bandyopadhyay and M. P. Deutscher, "Complex of aminoacyl-transfer RNA synthetases," Journal of Molecular Biology, vol. 60, no. 1, pp. 113-122, 1971. 
[53] O. Kellermann, H. Tonetti, A. Brevet, M. Mirande, J. P. Pailliez, and J. P. Waller, "Macromolecular complexes from sheep and rabbit containing seven aminoacyl-tRNA synthetases. I. Species specificity of the polypeptide composition," The Journal of Biological Chemistry, vol. 257, no. 18, pp. 11041-11048, 1982.

[54] S. Kim, S. You, and D. Hwang, "Aminoacyl-tRNA synthetases and tumorigenesis: more than housekeeping," Nature Reviews Cancer, vol. 11, no. 10, pp. 708-718, 2011.

[55] D. L. Johnson and D. C. H. Yang, "Stoichiometry and composition of an aminoacyl-tRNA synthetase complex from rat liver," Proceedings of the National Academy of Sciences of the United States of America, vol. 78, no. 7, pp. 4059-4062, 1981.

[56] J.-C. Robinson, P. Kerjan, and M. Mirande, "Macromolecular assemblage of aminoacyl-tRNA synthetases: quantitative analysis of protein-protein interactions and mechanism of complex assembly," Journal of Molecular Biology, vol. 304, no. 5, pp. 983994, 2000.

[57] M. Mirande, B. Cirakoğlu, and J. P. Waller, "Seven mammalian aminoacyl-tRNA synthetases associated within the same complex are functionally independent," European Journal of Biochemistry, vol. 131, no. 1, pp. 163-170, 1983.

[58] S. G. Park, K. L. Ewalt, and S. Kim, "Functional expansion of aminoacyl-tRNA synthetases and their interacting factors: new perspectives on housekeepers," Trends in Biochemical Sciences, vol. 30, no. 10, pp. 569-574, 2005.

[59] P. S. Ray, A. Arif, and P. L. Fox, "Macromolecular complexes as depots for releasable regulatory proteins," Trends in Biochemical Sciences, vol. 32, no. 4, pp. 158-164, 2007.

[60] J. M. Han, M. J. Lee, S. G. Park et al., "Hierarchical network between the components of the multi-tRNA synthetase complex: implications for complex formation," The Journal of Biological Chemistry, vol. 281, no. 50, pp. 38663-38667, 2006.

[61] N. Yannay-Cohen, I. Carmi-Levy, G. Kay et al., "LysRS serves as a key signaling molecule in the immune response by regulating gene expression," Molecular Cell, vol. 34, no. 5, pp. 603-611, 2009.

[62] J. Y. Kim, Y.-S. Kang, J.-W. Lee et al., "p38 is essential for the assembly and stability of macromolecular tRNA synthetase complex: implications for its physiological significance," Proceedings of the National Academy of Sciences of the United States of America, vol. 99, no. 12, pp. 7912-7916, 2002.

[63] M. J. Kim, B.-J. Park, Y.-S. Kang et al., "Downregulation of FUSE-binding protein and c-myc by tRNA synthetase cofactor p38 is required for lung cell differentiation," Nature Genetics, vol. 34, no. 3, pp. 330-336, 2003.

[64] S. V. Kyriacou and M. P. Deutscher, "An important role for the multienzyme aminoacyl-tRNA synthetase complex in mammalian translation and cell growth," Molecular Cell, vol. 29, no. 4, pp. 419-427, 2008.

[65] P. G. Zamecnik, M. L. Stephenson, C. M. Janeway, and K. Randerath, "Enzymatic synthesis of diadenosine tetraphosphate and diadenosine triphosphate with a purified lysyl-sRNA synthetase," Biochemical and Biophysical Research Communications, vol. 24, no. 1, pp. 91-97, 1966.

[66] A. Brevet, P. Plateau, B. Cirakoǧlu, J. P. Pailliez, and S. Blanquet, "Zinc-dependent synthesis of $5^{\prime}, 5^{\prime}$-diadenosine tetraphosphate by sheep liver lysyl- and phenylalanyl-tRNA synthetases," The Journal of Biological Chemistry, vol. 257, no. 24, pp. 14613-14615, 1982.

[67] E. Razin, Z. C. Zhang, H. Nechushtan et al., "Suppression of microphthalmia transcriptional activity by its association with protein kinase C-interacting protein 1 in mast cells," The Journal of Biological Chemistry, vol. 274, no. 48, pp. 34272-34276, 1999.

[68] Y.-N. Lee, H. Nechushtan, N. Figov, and E. Razin, “The function of lysyl-tRNA synthetase and Ap4A as signaling regulators of MITF activity in FceRI-activated mast cells," Immunity, vol. 20, no. 2, pp. 145-151, 2004.

[69] Y.-N. Lee and E. Razin, "Nonconventional involvement of LysRS in the molecular mechanism of USF2 transcriptional activity in FceRI-activated mast cells," Molecular and Cellular Biology, vol. 25, no. 20, pp. 8904-8912, 2005.

[70] Y. Ofir-Birin, P. Fang, S. P. Bennett et al., "Structural switch of lysyl-tRNA synthetase between translation and transcription," Molecular Cell, vol. 49, no. 1, pp. 30-42, 2013.

[71] M. Jiang, J. Mak, A. Ladha et al., "Identification of tRNAs incorporated into wild-type and mutant human immunodeficiency virus type 1," Journal of Virology, vol. 67, no. 6, pp. 3246-3253, 1993.

[72] J. Leis, A. Aiyar, and D. Cobrinik, "Regulation of initiation of reverse transcription of retroviruses," Cold Spring Harbor Monograph Archive, vol. 23, pp. 33-47, 1993.

[73] S. Cen, A. Khorchid, H. Javanbakht et al., "Incorporation of lysyl-tRNA synthetase into human immunodeficiency virus type 1," Journal of Virology, vol. 75, no. 11, pp. 5043-5048, 2001.

[74] H. Javanbakht, R. Halwani, S. Cen et al., "The interaction between HIV-1 Gag and human lysyl-tRNA synthetase during viral assembly," The Journal of Biological Chemistry, vol. 278, no. 30, pp. 27644-27651, 2003.

[75] M. Guo, R. Shapiro, G. M. Morris, X.-L. Yang, and P. Schimmel, "Packaging HIV virion components through dynamic equilibria of a human tRNA synthetase," Journal of Physical Chemistry $B$, vol. 114, no. 49, pp. 16273-16279, 2010.

[76] J. Mak, M. Jiang, M. A. Wainberg, M.-L. Hammarskjöld, D. Rekosh, and L. Kleiman, "Role of Pr160gag-pol in mediating the selective incorporation of tRNALys into human immunodeficiency virus type 1 particles," Journal of Virology, vol. 68 , no. 4 , pp. 2065-2072, 1994.

[77] R. Halwani, S. Cen, H. Javanbakht et al., "Cellular distribution of Lysyl-tRNA synthetase and its interaction with gag during human immunodeficiency virus type 1 assembly," Journal of Virology, vol. 78, no. 14, pp. 7553-7564, 2004.

[78] S. Cen, H. Javanbakht, M. Niu, and L. Kleiman, "Ability of wildtype and mutant lysyl-tRNA synthetase to facilitate tRNALys) incorporation into human immunodeficiency virus type 1," Journal of Virology, vol. 78, no. 3, pp. 1595-1601, 2004.

[79] F. Guo, J. Gabor, S. Cen, K. Hu, A. J. Mouland, and L. Kleiman, "Inhibition of cellular HIV-1 protease activity by lysyl-tRNA synthetase," The Journal of Biological Chemistry, vol. 280, no. 28, pp. 26018-26023, 2005.

[80] S. G. Park, H. J. Kim, Y. H. Min et al., "Human lysyl-tRNA synthetase is secreted to trigger proinflammatory response," Proceedings of the National Academy of Sciences of the United States of America, vol. 102, no. 18, pp. 6356-6361, 2005.

[81] D. G. Kim, J. W. Choi, J. Y. Lee et al., "Interaction of two translational components, lysyl-tRNA synthetase and p40/37LRP, in plasma membrane promotes laminin-dependent cell migration," The FASEB Journal, vol. 26, no. 10, pp. 4142-4159, 2012.

[82] P. Linder and E. Jankowsky, "From unwinding to clamping-the DEAD box RNA helicase family," Nature Reviews Molecular Cell Biology, vol. 12, no. 8, pp. 505-516, 2011.

[83] I. Iost, T. Bizebard, and M. Dreyfus, "Functions of DEAD-box proteins in bacteria: current knowledge and pending questions," Biochimica et Biophysica Acta, vol. 1829, no. 8, pp. 866-877, 2013. 
[84] P. Linder and F. V. Fuller-Pace, "Looking back on the birth of DEAD-box RNA helicases," Biochimica et Biophysica Acta, vol. 1829, no. 8, pp. 750-755, 2013.

[85] E. Jankowsky, "RNA helicases at work: binding and rearranging," Trends in Biochemical Sciences, vol. 36, no. 1, pp. 19-29, 2011.

[86] A. M. Pyle, "RNA helicases and remodeling proteins," Current Opinion in Chemical Biology, vol. 15, no. 5, pp. 636-642, 2011.

[87] L. Yang, C. Lin, and Z.-R. Liu, "P68 RNA helicase mediates PDGF-induced epithelial mesenchymal transition by displacing Axin from $\beta$-catenin," Cell, vol. 127, no. 1, pp. 139-155, 2006.

[88] C.-M. Cruciat, C. Dolde, R. E. A. de Groot et al., "RNA helicase DDX3 is a regulatory subunit of casein kinase 1 in Wnt- $\beta$ catenin signaling," Science, vol. 339, no. 6126, pp. 1436-1441, 2013.

[89] H. Hirling, M. Scheffner, T. Restle, and H. Stahl, "RNA helicase activity associated with the human p68 protein," Nature, vol. 339, no. 6225, pp. 562-564, 1989.

[90] Q. Yang and E. Jankowsky, “The DEAD-box protein Ded1 unwinds RNA duplexes by a mode distinct from translocating helicases," Nature Structural and Molecular Biology, vol. 13, no. 11, pp. 981-986, 2006.

[91] T. Sengoku, O. Nureki, A. Nakamura, S. Kobayashi, and S. Yokoyama, "Structural basis for RNA unwinding by the DEADbox protein Drosophila Vasa," Cell, vol. 125, no. 2, pp. 287-300, 2006.

[92] F. V. Fuller-Pace, "The DEAD box proteins DDX5 (p68) and DDX17 (p72): multi-tasking transcriptional regulators," Biochimica et Biophysica Acta, vol. 1829, no. 8, pp. 756-763, 2013.

[93] M. Botlagunta, F. Vesuna, Y. Mironchik et al., "Oncogenic role of DDX3 in breast cancer biogenesis," Oncogene, vol. 27, no. 28, pp. 3912-3922, 2008.

[94] M. Schröder, M. Baran, and A. G. Bowie, "Viral targeting of DEAD box protein 3 reveals its role in TBK1/IKK $\varepsilon$-mediated IRF activation," EMBO Journal, vol. 27, no. 15, pp. 2147-2157, 2008.

[95] D. Soulat, T. Bürckstümmer, S. Westermayer et al., “The DEADbox helicase DDX3X is a critical component of the TANKbinding kinase 1-dependent innate immune response," EMBO Journal, vol. 27, no. 15, pp. 2135-2146, 2008.

[96] H. Endoh, K. Maruyama, Y. Masuhiro et al., "Purification and identification of p68 RNA helicase acting as a transcriptional coactivator specific for the activation function 1 of human estrogen receptor $\alpha$," Molecular and Cellular Biology, vol. 19, no. 8, pp. 5363-5372, 1999.

[97] B. J. Wilson, G. J. Bates, S. M. Nicol, D. J. Gregory, N. D. Perkins, and F. V. Fuller-Pace, "The p68 and p72 DEAD box RNA helicases interact with $\mathrm{HDACl}$ and repress transcription in a promoter-specific manner," BMC Molecular Biology, vol. 5, article 11, 2004.

[98] C. Merz, H. Urlaub, C. L. Will, and R. Lührmann, "Protein composition of human mRNPs spliced in vitro and differential requirements for mRNP protein recruitment," $R N A$, vol. 13, no. 1, pp. 116-128, 2007.

[99] T. Burckin, R. Nagel, Y. Mandel-Gutfreund et al., "Exploring functional relationships between components of the gene expression machinery," Nature Structural \& Molecular Biology, vol. 12, no. 2, pp. 175-182, 2005.

[100] A. M. Owsianka and A. H. Patel, "Hepatitis C virus core protein interacts with a human DEAD box protein DDX3," Virology, vol. 257, no. 2, pp. 330-340, 1999.
[101] V. S. R. K. Yedavalli, C. Neuveut, Y.-H. Chi, L. Kleiman, and K.T. Jeang, "Requirement of DDX3 DEAD box RNA helicase for HIV-1 Rev-RRE export function," Cell, vol. 119, no. 3, pp. 381392, 2004.

[102] Y. Ariumi, M. Kuroki, K.-I. Abe et al., "DDX3 DEAD-box RNA helicase is required for hepatitis C virus RNA replication," Journal of Virology, vol. 81, no. 24, pp. 13922-13926, 2007.

[103] X. Zhou, J. Luo, L. Mills et al., "DDX5 facilitates HIV-1 replication as a cellular co-factor of Rev," PLoS ONE, vol. 8, no. 5, Article ID e65040, 2013.

[104] C.-S. Lee, A. P. Dias, M. Jedrychowski, A. H. Patel, J. L. Hsu, and R. Reed, "Human DDX3 functions in translation and interacts with the translation initiation factor eIF3", Nucleic Acids Research, vol. 36, no. 14, pp. 4708-4718, 2008.

[105] J.-W. Shih, T.-Y. Tsai, C.-H. Chao, and Y.-H. Wu Lee, "Candidate tumor suppressor DDX3 RNA helicase specifically represses cap-dependent translation by acting as an eIF4E inhibitory protein," Oncogene, vol. 27, no. 5, pp. 700-714, 2008.

[106] M. Schröder, "Human DEAD-box protein 3 has multiple functions in gene regulation and cell cycle control and is a prime target for viral manipulation," Biochemical Pharmacology, vol. 79, no. 3, pp. 297-306, 2010.

[107] H. S. Chahar, S. Chen, and N. Manjunath, "P-body components LSM1, GW182, DDX3, DDX6 and XRN1 are recruited to WNV replication sites and positively regulate viral replication," Virology, vol. 436, no. 1, pp. 1-7, 2013.

[108] S. C. Cloutier, W. K. Ma, L. T. Nguyen, and E. J. Tran, "The DEAD-box RNA helicase Dbp2 connects RNA quality control with repression of aberrant transcription," The Journal of Biological Chemistry, vol. 287, no. 31, pp. 26155-26166, 2012.

[109] C. Hooper and A. Hilliker, "Packing them up and dusting them off: RNA helicases and mRNA storage," Biochimica et Biophysica Acta, vol. 1829, no. 8, pp. 824-834, 2013.

[110] S. V. Puthanveettil, "RNA transport and long-term memory storage," RNA Biology, vol. 10, no. 12, 2013.

[111] A. Hilliker, Z. Gao, E. Jankowsky, and R. Parker, "The DEADbox protein Ded1 modulates translation by the formation and resolution of an eIF4F-mRNA complex," Molecular Cell, vol. 43, no. 6, pp. 962-972, 2011.

[112] J. Liu, J. Henao-Mejia, H. Liu, Y. Zhao, and J. J. He, “Translational regulation of HIV-1 replication by HIV-1 rev cellular cofactors Sam68, eIF5A, hRIP, and DDX3," Journal of Neuroimmune Pharmacology, vol. 6, no. 2, pp. 308-321, 2011.

[113] C. Lin, L. Yang, J. J. Yang, Y. Huang, and Z.-R. Liu, "ATPase/helicase activities of p68 RNA helicase are required for pre-mRNA splicing but not for assembly of the spliceosome," Molecular and Cellular Biology, vol. 25, no. 17, pp. 7484-7493, 2005.

[114] L. Yang, C. Lin, and Z.-R. Liu, "Signaling to the DEAD box-regulation of DEAD-box p68 RNA helicase by protein phosphorylations," Cellular Signalling, vol. 17, no. 12, pp. 14951504, 2005.

[115] Y.-J. Choi and S.-G. Lee, “The DEAD-box RNA helicase DDX3 interacts with DDX5, co-localizes with it in the cytoplasm during the G2/M phase of the cycle, and affects its shuttling during mrnp export," Journal of Cellular Biochemistry, vol. 113, no. 3, pp. 985-996, 2012.

[116] G. Davidson, J. Shen, Y.-L. Huang et al., "Cell cycle control of wnt receptor activation," Developmental Cell, vol. 17, no. 6, pp. 788-799, 2009.

[117] R. Nusse, "An ancient cluster of Wnt paralogues," Trends in Genetics, vol. 17, no. 8, p. 443, 2001. 
[118] B. Prud'homme, N. Lartillot, G. Balavoine, A. Adoutte, and M. Vervoort, "Phylogenetic analysis of the Wnt gene family: insights from lophotrochozoan members," Current Biology, vol. 12, no. 16, pp. 1395-1400, 2002.

[119] C. P. Petersen and P. W. Reddien, "Wnt signaling and the polarity of the primary body axis," Cell, vol. 139, no. 6, pp. 10561068, 2009. 

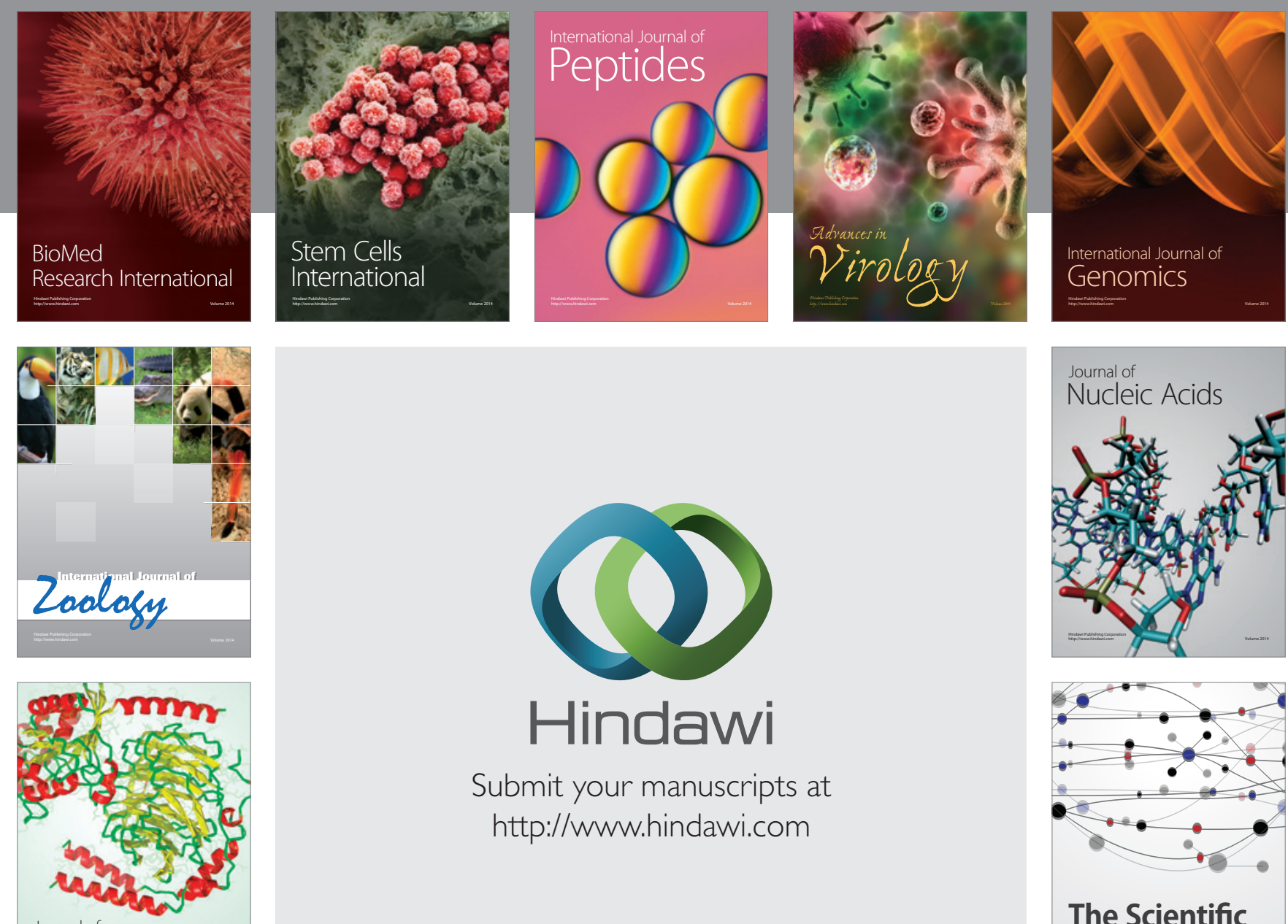

Submit your manuscripts at

http://www.hindawi.com

Journal of
Signal Transduction
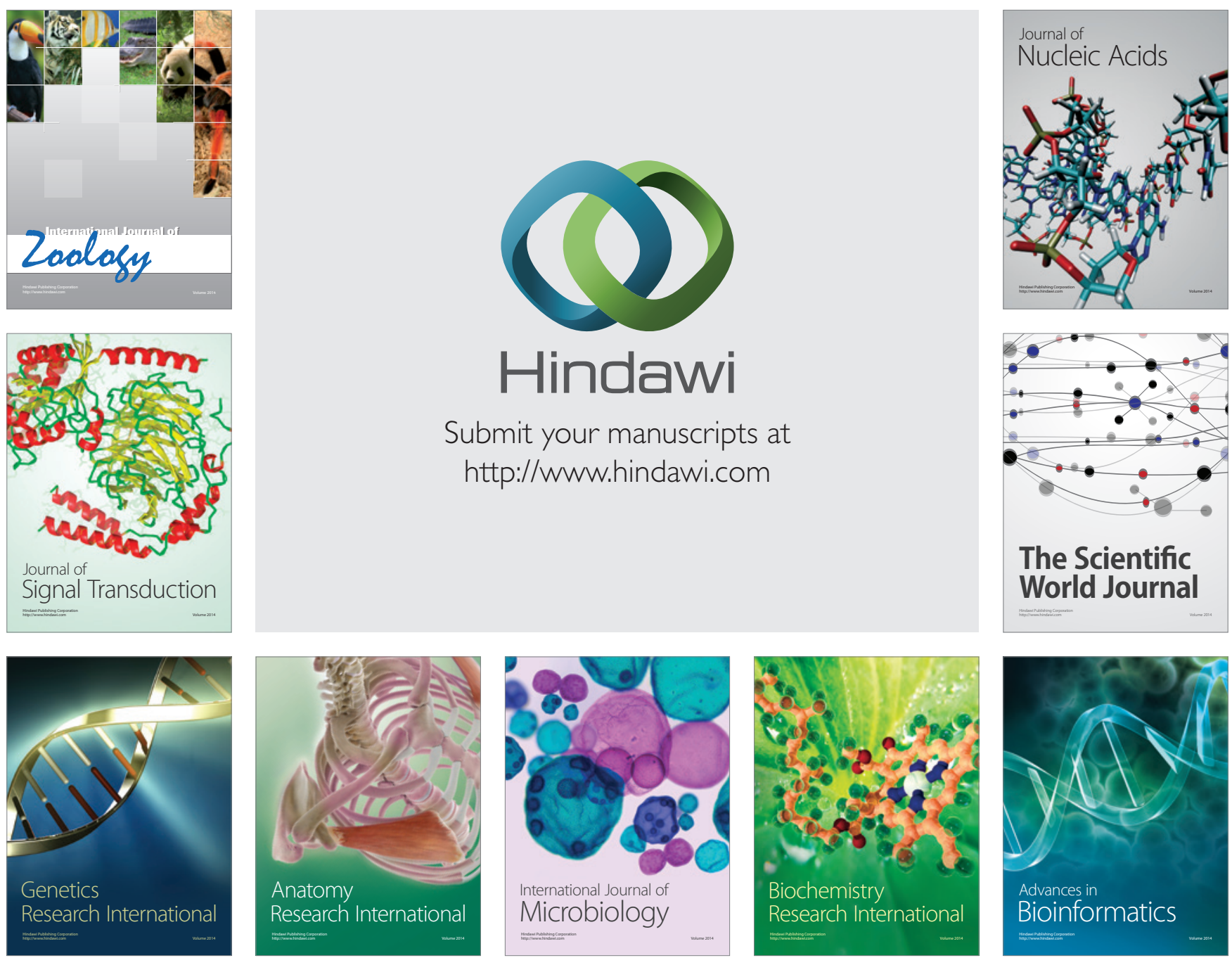

The Scientific World Journal
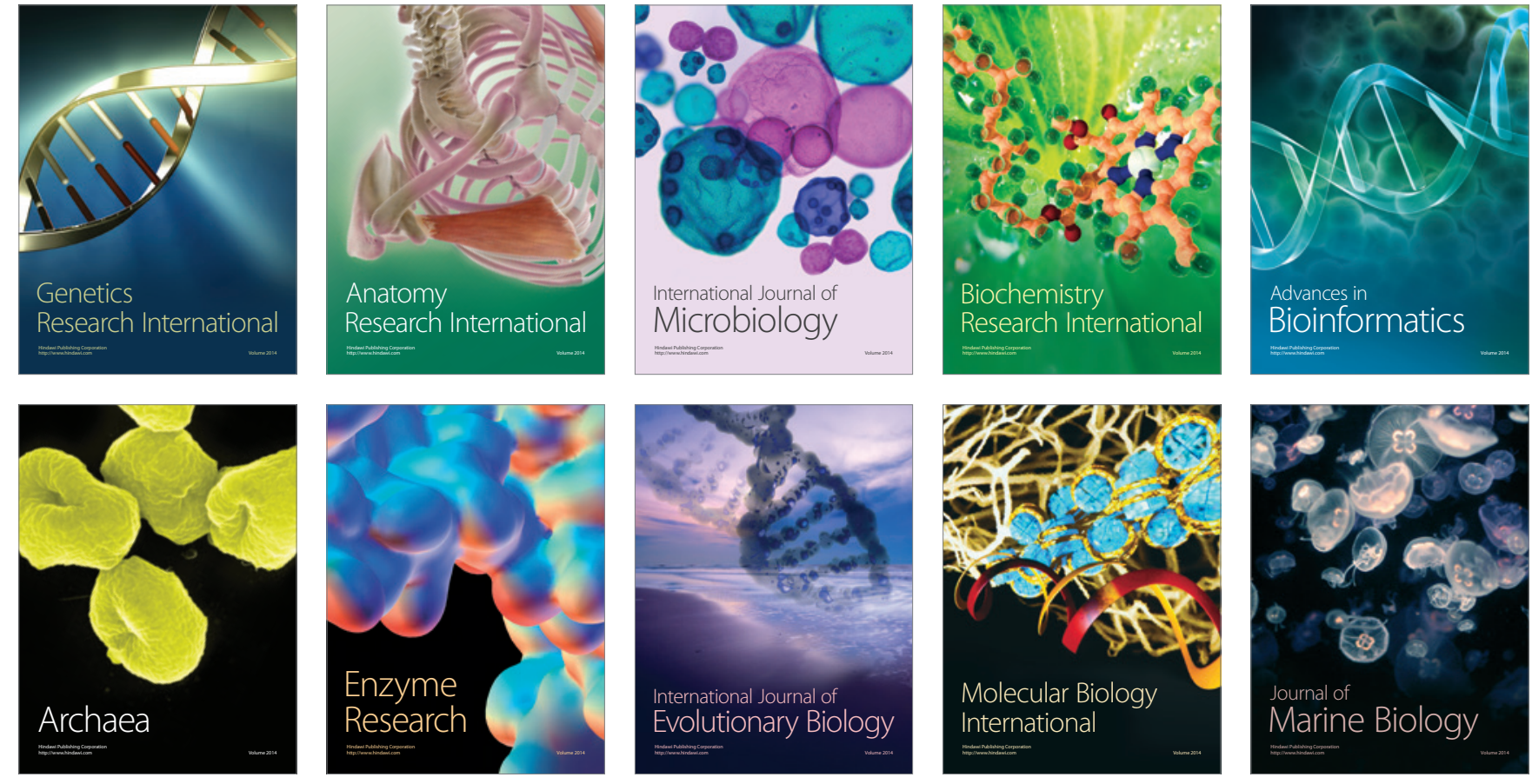